\title{
Reflexões sobre o Acordo Judicial e a Administração Institucional de Conflitos na Justiça do Trabalho.
}

\section{Reflections on the Judicial Negociacion and Institutional Administration of Conflicts in the Labor Court}

Fábio de Medina da Silva Gomes ${ }^{1}$

\section{RESUMO}

O Direito Processual do Trabalho é influenciado, fortemente, pelo Princípio da Conciliação, ou seja, entende-se que os acordos são um valor estruturante na Justiça do Trabalho. Nesse sentido, pretendi construir uma descrição densa sobre os acordos judiciais nas audiências trabalhistas, para isso, realizei uma observação direta, acompanhando essas sessões, bem como realizando entrevistas e convivendo com os interlocutores. Privilegiei, nesse trabalho de campo, as audiências envolvendo trabalhadoras domésticas remuneradas, problematizando também a legislação que informa esses contratos de trabalho. Além disso, observei a centralidade da figura do magistrado para alcançar esses acordos judiciais, acompanhando estudos sobre a lógica do contraditório.

\section{PALAVRAS-CHAVE:}

Justiça do Trabalho, Conciliação, Trabalho Doméstico Remunerado.

\begin{abstract}
Procedural Labor Law is strongly influenced by the Conciliation Principle, that is, it is understood that agreements are a structuring value in Labor Court. In this sense, I intended to build a dense description about the judicial agreements in the labor hearings, for that, I made a direct observation, following these sessions, as well as conducting interviews and living with the interlocutors. In this fieldwork, I favored hearings involving paid domestic workers, also problematizing the legislation that informs these employment contracts. In addition, I observed the centrality of the figure of the magistrate to reach these judicial agreements, following studies on the logic of the adversary..
\end{abstract}

\section{KEYWORDS:}

Labor Court, Conciliation, Remunerated Housework.

\footnotetext{
${ }^{1}$ Doutor em Antropologia pela Universidade Federal Fluminense (2020). Mestre em Direito Constitucional pela Universidade Federal Fluminense (2015). Bacharel em Ciências Jurídicas e Sociais pela Universidade Federal do Rio de Janeiro (2012). Pesquisador do Instituto de Estudos Comparados em Administração de Conflitos (INCT InEAC) e do Laboratório de Estudos sobre Conflitos, Cidadania e Segurança Pública (LAESP). Atualmente é professor substituto da Universidade do Estado de Mato Grosso - campus Renê Baubour.
} 


\section{INTRODUÇÃO}

A presente pesquisa se debruça sobre os discursos dos acordos judiciais na Justiça do Trabalho quando do julgamento que envolvia trabalho doméstico remunerado. Trabalhei, na minha dissertação, com julgamentos desses casos, e venho desenvolvendo esse tema e seus correlatos, em outros textos (GOMES, SILVA, 2020; GOMES, 2016a, 2016b, 2015a, 2015b). O trabalho doméstico remunerado, no Brasil, tem suscitado uma série de estudos em várias áreas do conhecimento (SAFFIOTI,1978; MELO,1998; BRUSCHINI, 2006; HIRATA, 2013; BRITTES, 2013 e muitos outros), e a minha contribuição se dá no sentido de entender os discursos propalados pela Justiça do Trabalho sobre o trabalho doméstico remunerado, na cidade de Niterói, Região Metropolitana do Rio de Janeiro.

Como, durante minha dissertação de mestrado, queria compreender a administração institucional de conflitos entre trabalhadoras domésticas remuneradas e seus empregadores, realizei uma pesquisa empírica nas Varas do Trabalho de Niterói. Para tanto, além de assistir as audiências, busquei conviver com uma série de interlocutores e realizei entrevistas semiestruturadas. Desse modo, advogados, juízes, empregadores domésticos, empregadas domésticas, diaristas, sindicalistas e técnicos judiciários participaram em alguma medida dessa pesquisa. Além de assistir as audiências ${ }^{2}$, passei várias tardes no prédio da Justiça do Trabalho em Niterói conversando com advogados e jurisdicionados pelos corredores, e realizei algumas entrevistas com juízes.

Quando comecei a observar as audiências, decidi por obedecer a uma rotina. Entrava no prédio onde se localizavam as Varas do Trabalho e subia a cada uma das Varas do Trabalho, que se localizavam uma em cada andar. Nesse momento, buscava a pauta de audiências do dia, e observava a listagem. Procurava pelas audiências cuja parte passiva era uma pessoa física, e não uma empresa, e anotava o número do processo. Depois, abria o processo, que estava quase sempre na mesa do juiz, verificava se tratava de um processo envolvendo trabalhadoras domésticas, e ficava na sala de audiências junto com muitas outras pessoas esperando. Chamei essas audiências de "audiências sobre domésticas" ou "audiências sobre trabalho doméstico". Utilizei assim, a expressão "doméstica", como explicarei melhor, significando todo o tipo de

\footnotetext{
${ }^{2}$ Refiro-me tanto as audiências sobre trabalho doméstico quanto às outras.
} 
trabalhadora doméstica remunerada, conforme os interlocutores classificavam. Uma "doméstica" pode ser empregada doméstica ou diarista, essa categorização era ressaltada pelas próprias domésticas.

Com o tempo, fui me apresentando aos juízes e explicava que fazia uma pesquisa de mestrado. De forma geral, eles gostavam e participaram com entrevistas e inclusive me recebendo num horário especificado. Alguns deles me davam abertura para fazer perguntas e considerações. Além disso, me aproximava dos empregadores e das trabalhadoras domésticas geralmente depois das audiências e conversávamos sobre o processo.

Dessa forma, construí dados com esses interlocutores sobre vários discursos que circulavam nas audiências. Falava-se de muitos temas, entre eles, dos acordos judiciais. Pretendo descrever como eram estabelecidos os acordos nessas audiências especificas sobre trabalho doméstico remunerado.

\section{EMPREGADAS DOMÉSTICAS OU DIARISTAS?}

Em um dia de trabalho de campo, fui ao Sindicato dos Empregados Domésticos, em Niterói. O sindicato funcionava numa sala pequena no centro da cidade. Durante a conversa com a presidente, obtive importantes indicações sobre problemas recorrentes. Existiam dificuldades práticas que poderiam ser percebidas durante as audiências. A primeira questão colocada por ela me pareceu muito importante, era o reconhecimento de vínculo de emprego. Numa relação de trabalho dentro de uma casa há dificuldade de encontrar testemunhas que atestem uma relação de continuidade, como requerido pelos tribunais.

Essa questão da dificuldade de comprovação do vínculo empregatício remete, inevitavelmente, a reflexões sobre a Emenda Constitucional no 72 de 2013 (EC 72/2013). Ela tratou de aumentar o número de direito dos empregados domésticos, para incluir: o direito a duração do trabalho normal não superior a oito horas diárias e quarenta e quatro semanais, remuneração do serviço extraordinário em cinquenta por centro à do normal, reconhecimento das convenções e acordos coletivos de trabalho, entre outros, muitos dos quais regulamentados 
pela Lei Complementar 150 de 2015. Essa nova legislação revogou a Lei 5.859 de 1972, antiga lei de trabalho doméstico, implementando importantes modificações.

Para muitos, essa legislação significou a garantia do trabalho decente. Por outro lado, a jurisprudência da Justiça do Trabalho dificultou a comprovação do vínculo de emprego. Cuidava-se de um debate antigo entre a diferença do termo "não-eventual", constante no Artigo $3^{\circ}$ da Consolidação das Leis do Trabalho e do termo "natureza contínua", segundo o antigo Artigo $1^{\circ}$ da Lei 5.859 de 1972 . A Lei Complementar 150 de 2015 terminou com essa polêmica ao determinar que é empregado doméstico quem presta o seu serviço "por mais de 2 (dois) dias por semana".

Esse debate, suscitado em muitas audiências, é importante para entender a grande quantidade de acordos, haja vista que a empregada doméstica deveria conseguir provar que trabalhou na casa do empregador por mais de dois dias por semana. Tratava-se de uma prova difícil de ser realizada, ainda mais porque tal atividade se realiza no âmbito da casa, ou seja, com poucas pessoas acompanhando. Assim, os advogados das trabalhadoras domésticas receavam não conseguir provar o vínculo de emprego. Enquanto, por sua vez, os empregadores temiam o contrário.

Nesse sentido, a sociedade brasileira, ao administrar esse conflito criou três categorias: a diarista, a empregada doméstica e a doméstica. A primeira não tem vínculo de emprego, são profissionais autônomas, tendo poucos direitos. A empregada tem o vínculo de emprego, com mais direitos. Podendo ter ou não a sua formalização do contrato de emprego, sua Carteira de Trabalho e Previdência Social (CTPS) assinada pelo empregador. A última categoria é simplesmente doméstica, ela identifica tanto a diarista quanto a empregada doméstica. É uma forma de se referir ao trabalho doméstico remunerado de qualquer espécie. Embora essas diferenciações apresentem alguma certeza, na prática, não há essa certeza, devido à dificuldade de comprovação do vínculo empregatício.

Regina Lúcia Teixeira Mendes (2008) demonstrou como duas cosmovisões paradoxais sobre cidadania convivem sem maiores constrangimentos, no Brasil. Embora tenhamos um discurso de uma democracia liberal (tal como as regras constitucionais sobre liberdades civis), temos, concomitantemente, práticas jurídicas e sociais obedecendo à ética de sociedades hierarquizadas e desiguais (como foro privilegiado por prerrogativa de função e aposentadorias especiais de juízes). 
Segundo a autora, entre os juristas, esse paradoxo brasileiro foi naturalizado. Invocando as lições de Ruy Barbosa, formulou-se uma interpretação peculiar do princípio da isonomia. Para ele, a igualdade era tratar desigualmente os desiguais, na medida de sua desigualdade. Ruy Barbosa não distinguiu desigualdades de diferenças. Ficaram, dessa forma, explicados diversos tratamentos privilegiados a segmentos mais favorecidos.

Não me refiro aqui às políticas públicas para superação de desigualdades, como a instauração de cotas raciais nas universidades federais ou do tempo de aposentadoria diferenciado para as mulheres. Em muito se avançou, por exemplo, com a Lei Maria da Penha, outro exemplo de discriminação positiva. Mas a minha questão não é essa.

O problema levantado foi: como pode o instituto da igualdade conviver com discriminações como o instituto da prisão especial, foro privilegiado e aposentadoria especial dos magistrados. São discriminações que favorecem setores abastados da sociedade, desprezando os mais pobres. Trata-se de leis que em nada contribuem para superar as desigualdades, antes são evidentemente para mantê-las. Esse é o caso da Consolidação ao tratar das empregadas domésticas. Acomodadas nas lições de Ruy Barbosa, as desigualdades foram estabelecidas, no imaginário jurídico brasileiro, como uma situação natural.

Ruy Barbosa argumentou que,

A parte da natureza varia ao infinito. Não há, no universo, duas coisas iguais. Muitas se parecem umas às outras. Mas todas entre si diversificam. Os ramos de uma só árvore, as folhas da mesma planta, os traços da polpa de um dedo humano, as gotas do mesmo fluido, os argueiros do mesmo pó, as raias do espectro de um só raio solar ou estelar. Tudo assim, desde os astros no céu, até os micróbios no sangue, desde as nebulosas no espaço, até aos aljôfares do rocio na relva dos prados.

A regra da igualdade não consiste senão em aquinhoar desigualmente aos desiguais, na medida em que se desigualam. Nesta desigualdade social, proporcionada à desigualdade natural, é que se acha a verdadeira lei da igualdade. O mais são desvarios da inveja, do orgulho, ou da loucura. Tratar com desigualdade a iguais, ou a desiguais com igualdade, seria desigualdade flagrante, e não igualdade real. Os apetites humanos conceberam inverter a norma universal da criação, pretendendo, não dar a cada um, na razão do que vale, mas atribuir o mesmo a todos, como se todos se equivalessem. (BARBOSA, 1956, p. 56)

Assinale-se o contraste da cidadania brasileira, marcada pela naturalização da desigualdade, com o ideário da cidadania em outras sociedades. O ideário dos indivíduos iguais 
numa sociedade liberal está contido nas ideias de cidadania. Contudo, entre nós, como depositários da herança ibérica, os direitos não eram conquistas, mas outorga da coroa, com o objetivo de promover a compensação da desigualdade jurídica naturalizada. Ao invés de extirpar as desigualdades sociais, o nosso modelo de cidadania procura acomodar as desigualdades. (MENDES, 2008)

\title{
3. AS AUDIÊNCIAS SOBRE O TRABALHO DOMÉSTICO REMUNERADO
}

\author{
Juiz do Trabalho: - Tem acordo? Vocês aceitam um acordo de R\$ 800? Olha lá, \\ conforme for instruindo vai ficar mais distante para os dois lados! \\ Advogado da Reclamada: Nós aceitamos R \$ 500. \\ Juiz do Trabalho: - A senhora aceita? (se dirigindo a empregada). O seu processo é de \\ pequeno valor e isso daqui pode subir. Acho melhor aceitar. \\ Empregada: - Não sei. (fala muito baixa). \\ Advogado da Reclamante: Se for de 750 nós aceitamos. \\ Juiz do Trabalho: - A senhora aceita? (se dirigindo a empregada). \\ Empregadora: - Não sei. (fala muito baixa). \\ Juiz do Trabalho: - Então eu vou deixar vocês quinze minutos lá fora, pensando sobre \\ o acordo. Enquanto isso eu vou fazendo outra audiência. Quando voltarem, eu quero \\ um acordo. \\ (Passado o tempo as partes retornam para a sala de audiência) \\ Juiz do Trabalho: - Então, fecharam o acordo? \\ Advogado da Reclamante: Sim.
}

Durante toda essa audiência, como observei outras vezes, a Reclamante e a Reclamada não se entreolhavam. Esse acordo foi homologado sem problemas pelo juiz. Essa foi uma das muitas audiências assistidas durante a minha pesquisa. Resolvi trazê-la para enfatizar a questão dos discursos sobre administração institucional de conflitos. Para os advogados e o juiz, essa era apenas mais uma audiência, uma cena do seu cotidiano. Para a doméstica e a empregadora cuidava-se de uma ruptura com o cotidiano. Elas "foram à justiça", expressão repetida por vários jurisdicionados. As duas facetas dessa expressão, quais sejam, "procurar direitos" ou "se defender”, apontam para um cenário de cobrança.

A figura de liderança do juiz se exerce de forma peculiar nessa relação. E isso gera uma situação de receio. Repetidas vezes, nas conversas com as trabalhadoras domésticas depois das audiências, elas demonstraram medo do juiz. Além disso, eles chamavam atenção das domésticas "para elas cobrarem mais" dos seus advogados, dado que alguns advogados 
faltavam à audiência. Cheguei a ouvir de certo juiz sobre a necessidade de se neutralizar a figura do advogado.

O acordo é algo muito importante no judiciário trabalhista. Contudo, a doméstica geralmente não opinava nesse valor, quem opina é o juiz, o advogado da doméstica, o advogado do empregador e o empregador. Em certa audiência, a empregada doméstica, antes de firmar o acordo, queria falar sobre as férias. "As férias que estão aí, ..." Imediatamente foi interrompida pelo juiz. "Isso nós não vamos falar. Primeiro vamos ver se temos acordo."

Certo dia, houve uma audiência que me chamou atenção. No começo, o juiz perguntou se as partes já haviam chegado com um acordo. O advogado da empregadora propôs um acordo, mil e quinhentos reais, parcelados em seis vezes. Enquanto os advogados e o juiz conversavam, a doméstica se dirigiu à empregadora. "Esquece eles. Olha para mim, vamos ver um valor entre nós. Um valor pequeno desses dividido em seis vezes!?" A empregadora retrucou. "Você sabe que eu não posso mais". Por fim, estabeleceram o acordo de mil e seiscentos reais, parcelado em quatro vezes. O que mais me chamou atenção nessa história toda foram alguns advogados que assistiam àquela audiência comigo. Eles esperavam durante alguns minutos por suas audiências. Segundo eles, era "um absurdo as pessoas discutirem valores de acordo sem a opinião de seus advogados ou do juiz" e "um desrespeito ela falar que o valor era pequeno".

Observei, ainda, haver acordos estipulados de forma tão rápida que se torna um desafio para minha pesquisa. Alguns advogados já levam acordos feitos antes das audiências. Os juízes apenas homologam. Como ouvi recentemente de uma juíza para os advogados, "a qualquer hora que vocês trouxerem um acordo aqui, eu homologo. Faço audiências de segunda à quinta". Como chamaram atenção Oliveira e Freitas (2020), muitos acordos eram acertados antes mesmo das audiências.

Nesse período de trabalho de campo, pude perceber que o mecanismo das audiências é bem repetitivo, tudo se desenrola em torno do acordo. Como os valores das ações das domésticas são pequenos, pois elas recebem menos que outras ocupações e a comprovação do vínculo é algo complexo, geralmente, há um acordo. Os acordos são comuns também em outras categorias, mas entre as domésticas é quase a totalidade das ações que acompanhei.

Os acordos se colocam como forma especial e privilegiada de administrar esses conflitos. Shelton Davis (1973) esclarece três proposições gerais vistas em várias sociedades 
sobre dívida e contrato. Segundo ele, em toda a sociedade há um corpo de categorias culturais, de regras/códigos, definindo direitos e deveres entre os homens. Quando essas regras são rompidas surgem disputas, conflitos. As sociedades elaboram meios institucionalizados para administrar conflitos, nos quais as regras jurídicas são reafirmadas e/ou redefinidas. A resolução institucional de conflitos é objeto de estudo da Antropologia do Direito. Cabe-nos perguntar qual a forma de resolução de conflitos está-se utilizando nesse caso.

Longe de um acordo entre as partes apenas, trata-se de uma dinâmica em que a figura do juiz é muito presente. Os acordos não se dão entre as partes, livremente. Os juízes propõem valores desde o começo das audiências. Há verdadeira preocupação entre todos, advogados, empregadores, juízes em fazer um acordo. Enquanto isso, a trabalhadora doméstica pouco opina. Geralmente elas têm dúvidas sobre se o acordo é benéfico. Contudo, é sempre chamada pelo juiz. “A senhora aceita a proposta?” A resposta quase sempre é: "Não sei”. Comumente se houve o juiz retrucar: "Mas, olha... tem certeza?" Assisti a uma audiência em que o juiz falou para o advogado da doméstica. "O senhor é mais instruído do que ela. Explique a ela as razões da necessidade desse acordo". E o fim da história se repete com a aceitação do acordo pela trabalhadora.

Clarice Gontarski Speranza (2013) citou importante e rara obra de Arnaldo Süssekind, importante autor do campo jurídico, intitulada "Manual da Justiça do Trabalho", de 1942. Ainda nesse período, o referido autor já instruía aos juízes do trabalho "propor e insistir na conciliação, antes de qualquer apreciação da causa, e, mais tarde, logo após a instrução do dissídio, isto é, antes de proferir a decisão.” (SÜSSEKIND APUS SPERANZA, 2013, p. 52)

Nesse mesmo sentido, o discurso oficial do Poder Judiciário sobre a conciliação foi ainda mais contundente. O Conselho Superior da Justiça do Trabalho, realizou campanhas com vistas a reforçar a conciliação. A parte visual da campanha contou com banners, posts para o facebook, spot e um pequeno filme. O ato de conciliar foi comparado ao ato de estender as mãos. 


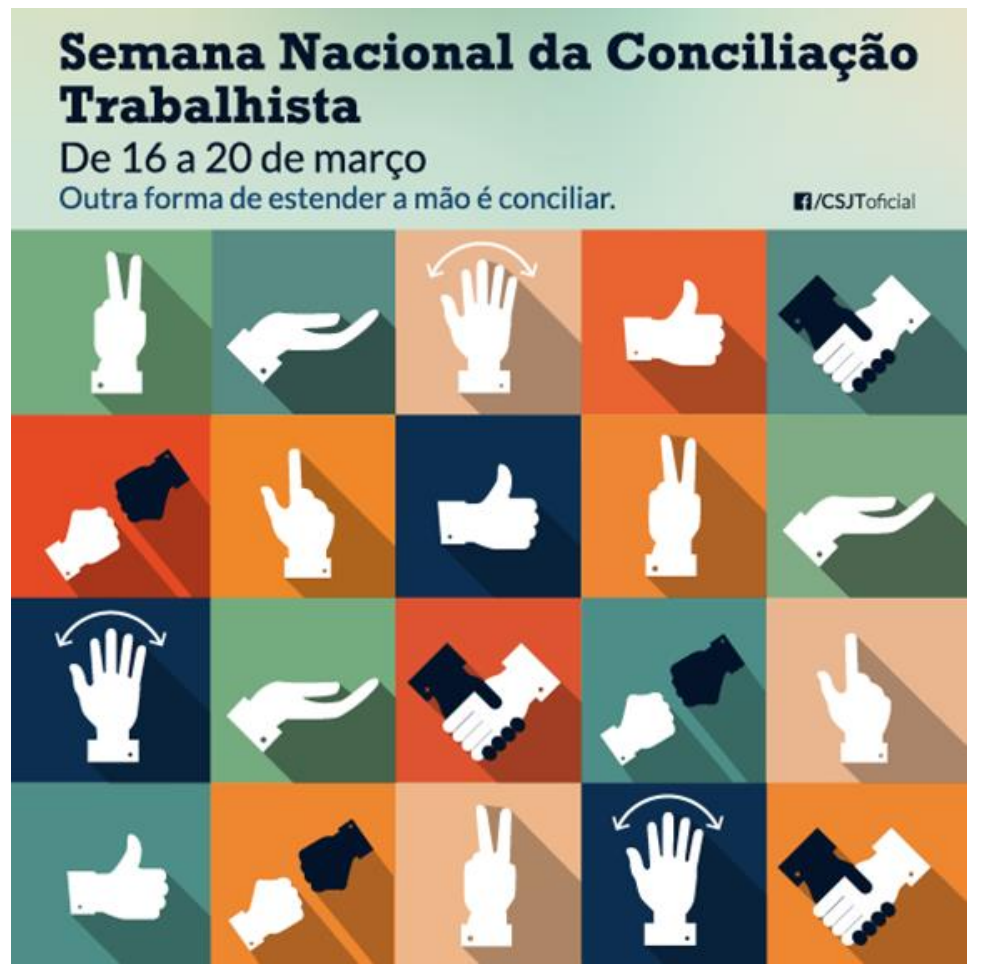

Figura 01 - Campanha da Semana Nacional de Conciliação

\section{A JUSTIÇA DO TRABALHO E AS CONCILIAÇÕES}

O discurso oficial empregou ênfase tanto na informalidade quanto na conciliação. Para reafirmar isso, inúmeros símbolos remeteram a outra época. De forma diferente de outras justiças, o que devia acompanhar a petição inicial não era a carteira de identidade, mas a Carteira de Trabalho e Previdência Social (CTPS). Ela também devia ser trazida pelas testemunhas como o documento de identificação.

Ângela de Castro Gomes e Fernando Teixeira da Silva (2013) fizeram importantes considerações sobre a história da Justiça do Trabalho. Tratava-se de um projeto do grupo político vencedor da Revolução de 1930. Embora com previsão expressa nas Constituições de 1934 e 1937, essa Justiça começou a funcionar apenas em $1^{\circ}$ de Maio de 1941, durante o Estado Novo. Entre os articuladores políticos dentro e fora da Assembleia Constitucional de 1933 estavam Waldemar Falcão e Oliveira Viana. Fato importante foi que entre 1941 e 1946, a Justiça do Trabalho foi uma justiça administrativa. Ela era parte do Poder Executivo. 
E nesses primeiros cinco anos, a Justiça do Trabalho conviveu com as ideias de autoritarismo e corporativismo como guia para uma suposta paz social. E não apenas conviveu com essas questões, mas compunha como parte estruturante do próprio Estado Novo. Era viva a concepção de uma conciliação entre as classes sociais, entre trabalhadores e empregadores. Assim, os autores destacaram ainda, algumas características dessa Justiça, dentre elas, a Oralidade e a Conciliação.

Desse período até a atualidade, o número de acordos nessa Justiça permaneceu elevado. Clarice Gontarski Speranza (2013) estudou os acordos judiciais entre mineiros de carvão e empregadores, no Rio Grande do Sul, entre 1946 e 1954. Apenas no ano de 1947, a percentagem de acordos sobre processos impetrados pelos trabalhadores era de 83,93\%. Adalberto Moreira Cardoso e Telma Lage (2007) estudaram a instituição da Justiça do Trabalho, com ênfase na sua capacidade de regulação do mercado de trabalho. Os autores ressaltaram algumas características centrais dessa justiça no seu desenho original, dentre elas a informalidade, a conciliação e a celeridade.

Quanto à informalidade, frisam a redação do artigo 839 da Consolidação, dispondo sobre a possibilidade de o empregado realizar reclamação verbal, sem assistência de advogado. O empregado ia à Justiça do Trabalho, falava que tinha uma reclamação, o servidor tomava nota e começava o processo. Isso se chama redução à termo. Mencionam ainda uma linguagem menos técnica. O termo ação era substituído por reclamação, por exemplo.

Já no que tange à conciliação Cardoso e Lage (2007) relembram a própria composição original das Juntas de Conciliação e Julgamento (atuais Varas do Trabalho) auxiliava na busca da conciliação. Havia um juiz de direito e outros dois juízes classistas, ou seja, indicados pelos representantes dos empregadores e dos empregados.

Esses autores apontam para outra característica, muito repetida por advogados e juízes no trabalho de campo. A celeridade da Justiça do Trabalho. Cardoso e Lage (2007) sublinham o "Princípio da Audiência Una", como explicitado na Consolidação, em seu artigo 849. No desenho original do processo do trabalho, o empregador ia até a Justiça e fazia sua reclamação, daí os termos, "Reclamação Trabalhista", "Reclamado" e "Reclamante". Em dois dias, o empregador era notificado. Em cinco dias após, os empregados e empregadores deveriam comparecer à Justiça com testemunhas e documentos. A ideia era que a demanda fosse ali decidida, na "Audiência Uma”. Atualmente, as outras justiças deram importância à questão da 
celeridade, especialmente após a Emenda Constitucional n ${ }^{\circ} 45$ de 2004. Mas o certo é que esse ideário da celeridade continuou muito mais acentuado na Justiça do Trabalho.

Havia, no entanto, uma massa trabalhadora, durante o Estado Novo, que estava alijada de todos os benefícios sociais trazidos pela assinatura da carteira de trabalho. Caso clássico dos trabalhadores rurais. Inclusive a possibilidade de propor "Reclamação Trabalhista" nessa justiça administrativa. (SILVA, 2008)

A celeridade, a informalidade e a conciliação não eram discursos isolados no tempo. Aqueles advogados e juízes que, durante a minha pesquisa de campo, defenderam a instituição da Justiça do Trabalho como célere, informal e conciliatória, não o fizeram por acaso. Não o fizeram de forma deslocada de outros discursos oficiais. Mas como eram, na prática social, essa administração de conflitos e esses acordos? Qual a relação desses discursos oficiais com os casos expostos?

\section{PROBLEMATIZANDO A PRÁTICA DO ACORDO}

Durante a minha pesquisa, três textos foram fundamentais para compreender e problematizar essas práticas sociais desses acordos ${ }^{3}$. O primeiro, de autoria de Roberto Kant de Lima, "Sensibilidades jurídicas, saber e poder: bases culturais de alguns aspectos do direito brasileiro em uma perspectiva comparada". O outro, de autoria de Pedro Heitor de Barros Geraldo, "A Audiência Judicial Em Ação: uma etnografia das interações entre juristas e jurisdicionados na França”. E, por fim, "Harmonia Coerciva: A economia política dos modelos jurídicos", de Laura Nader.

Roberto Kant de Lima (2009) fez referência expressa à Clifford Geertz e ao conceito de sensibilidades jurídicas. Tratou-se de um trabalho comparado que coloca em relevo o processo judiciário brasileiro. As sensibilidades jurídicas tinham relação com o sentimento de justiça que cada cultura estabelece. Ou seja, representou as bases culturais do direito. E elas variavam

\footnotetext{
${ }^{3}$ Embora, muitas outras pesquisas me auxiliaram para compreensão das dinâmicas das audiências (RANGEL, LIMA, 2010; TOLEDO LIMA, 2014; FONTAINHA, 2010).
} 
imensamente, não apenas em graus de definição, mas também no poder sobre fatos da vida cotidiana, surgindo diferentes formas de apresentar os fatos judicialmente.

Roberto Kant de Lima (2009) ressaltou as formas institucionais de produção e reprodução do saber jurídico nos Estados Unidos e no Brasil. Contrastou as duas lógicas imperantes nos judiciários desses lugares. Nos EUA, a lógica adversarial; no Brasil, a lógica do contraditório. A primeira é fundada num consenso provisório, construído por reflexões e explicações de diferentes perspectivas dos envolvidos. Os fatos demonstrados em juízo são um consenso entre as partes.

A lógica do contraditório, imperante no direito processual brasileiro, tinha relação com um dissenso infinito, apenas finalizado com a palavra de uma autoridade maior e externa ao processo. E isso foi muito perceptível no caso brasileiro, dado que, entre nós, não apenas o direito é decidido em juízo, como também os fatos. O juiz devia julgar entre duas versões apresentadas. E deve formular uma terceira ou ratificar uma das duas versões sobre os fatos. Por isso, as palavras do juiz ao dizer que o advogado deve ser neutralizado. O advogado sempre se apresentou como uma possível mentira.

Diferente das evidences norte-americanas, há, no Brasil, uma outra lógica, que não visa consensualizar fatos, antes, se desenvolve num contraditório sem fim entre teses opostas que só é terminada pelo livre convencimento motivado do juiz. Desse modo, temos dois princípios importantes, também ensinado nos bancos de faculdade que devem ser explanados para a melhor compreensão desse tipo específico de administração institucional de conflitos. $\mathrm{O}$ primeiro é o princípio do contraditório, e o outro é o princípio dispositivo ou do livre convencimento motivado do juiz.

"O advogado da Reclamante sempre vai pedir tudo. (...) Por sua vez, o advogado da Reclamada sempre fala que está tudo pago." Essa fala foi de um juiz do trabalho durante a pesquisa, e, não era uma opinião apartada de outras representações. Esse discurso era ratificado por muitos magistrados, sobretudo quando da prática das audiências de conciliação.

Outro aspecto levantado por Kant de Lima é a perspectiva da legitimidade. Na lógica adversarial, a legitimidade é fundada por aqueles que obedecem, seja por estar obrigado a obedecer, seja por querer obedecer. Isso também contrastou com a legitimidade dos sistemas da civil law. Neles, a racionalidade abstrata e os julgamentos técnicos conferiam legitimidade. 
Essa racionalidade técnica fez surgir outra racionalidade, subalterna. A crença na legitimidade ocorria mais ou menos como uma missa em latim. Tal como os fiéis, os jurisdicionados não entendiam os termos técnicos, mas acreditavam na ritualística do que estão acontecendo.

A relação dos jurisdicionados com a justiça e seus operadores, nos remete ao texto de Pedro Heitor de Barros Geraldo (2013). Sua pesquisa versou sobre as audiências e os juízes de proximidade na França, propondo uma análise do encontro entre juristas e jurisdicionados. $\mathrm{O}$ autor entendeu a audiência como objeto de pesquisa pouco comum, mas útil para compreender as práticas dos profissionais do direito. Sua observação centrou-se no questionamento da retórica e formalidade como base do trabalho do direito. Levantou questões, também, sobre um entendimento comum no qual o papel dos juristas seria reconhecer o direito e explicitá-lo de forma elegante e convincente.

As audiências estudadas pelo autor diferenciam-se muito das audiências que eu presenciei nesse trabalho de campo. Nesse tribunal francês, são vários os processos instruídos e julgados nas mesmas audiências. Enquanto, no Brasil, cada audiência corresponde a um processo. E assim se dá na França para realização de um procedimento pedagógico. A ideia era que os jurisdicionados, vendo os outros processos serem julgados soubessem como agir. No Brasil, raramente há essa plateia, as pessoas, geralmente chegam para sua audiência e, após, vão embora. Nesse sentido, verifiquei durante a pesquisa de campo uma questão. Por conta do calor nos corredores do tribunal e por outros fatores, as salas de audiência ficam cheias. Havia dias que eu não tinha onde sentar tanta era a plateia ${ }^{4}$ assistindo a audiência. Essa plateia era muito barulhenta e, geralmente estava ali apenas para passar o tempo até a sua audiência.

Isso foi explicado pela característica opaca e empírica da nossa sensibilidade jurídica, como quer Roberto Kant de Lima (2009). Realmente, a grande comunicação dos jurisdicionados era com seu advogado. Ele não apenas tinha o papel de defender a parte, mas devia explicar esses detalhes opacos, pouco palpáveis para quem fosse leigo em direito. Apesar da previsão legal do trabalhador poder se defender em juízo, sem a presença de advogado, isso não ocorreu em nenhuma das audiências assistidas. Em todos os casos houve a assistência dos advogados.

\footnotetext{
${ }^{4}$ Uso o termo plateia, como quer Goffman (2013).
} 
Ocorria, algumas vezes algo interessante, nas audiências sobre trabalho doméstico remunerado. Visto que havia atrasos de, às vezes, mais de uma hora nos horários das audiências, os advogados faltavam. Cumpria assim, à juíza, explicar o que a empregada doméstica deveria fazer. Assim foi com Ana. O advogado dela tinha faltado, no que a juíza se prontificou em explicá-la em detalhes o que deveria fazer. "Olha, a senhora dá uma bronca no seu advogado, se ele faltar de novo, teremos problemas. E esse papel você entrega na mão dele. Aqui é a data da audiência futura." Apesar de todo esse tratamento do juiz, quando perguntada sobre o ocorrido, Ana disse-me: "Meu advogado não veio, sentia muito medo do juiz, daquela posição, de tudo. Me sentia desamparada, mas Deus estava comigo. E Deus sabe que eu estava limpa diante dele."

A figura da autoridade que Ana enfrentou a amedrontava. E assim também foi para outras domésticas no tribunal. O judiciário, com seus símbolos opacos, palavras-chaves de difícil compreensão, tornou-se um lugar onde apenas Deus poderia agir para ajudar Ana. Ou pelo menos, assim ela percebia. Não era raro que as domésticas entrevistadas temessem aquele ambiente.

Por fim, analisei o texto de Laura Nader (1994). Essa pesquisadora estudou sobre a harmonia como técnica para pacificação. A autora delineia sua compreensão sobre o tema em três ambientes distintos: entre os zapotecas, no México; entre os norte-americanos, no intervalo de 1975 até os dias atuais e; por fim, no cenário internacional.

A sua ideia com essas pesquisas era colocar em relevo o significado da harmonia na administração institucional de conflitos, em diferentes realidades empíricas. Ela percebeu que, nos EUA, desde o final da década de 1970, havia uma apatia política, contrastando com a intensidade das décadas anteriores. A Justiça deixou de ser a pauta do dia. A harmonia e a eficiência passaram a fazer parte de um debate central.

A Alternative Dispute Resolution (ADR) enfatizou programas não judiciais para lidar com conflitos. A mediação e a arbitragem apareciam como uma espécie de justiça informal. A “expressão vencer ou vencer" é uma constante nesse discurso. Esse modelo veio com o intuito de substituir o litígio. Criou-se a ideia de um consenso homogêneo, uma concórdia. Nesse sentido, foi construída toda uma retórica aproximando a ADR à paz e a disputa judicial à guerra. E isso se deu forma capilarizada nos Estados Unidos, nas escolas, lares, hospitais, empresas e 
locais de trabalho. Alguns desses casos relatados pela autora me chamaram atenção para a presente pesquisa ${ }^{5}$.

No meu trabalho de campo, os acordos também ganharam papel relevante. Segundo muitas conversas com vários advogados trabalhistas no campo, além de alguns juízes, o número de acordos na Justiça do Trabalho era elevado. Nos processos em que eram partes as domésticas os valores das indenizações eram pequenos e, muitas vezes, a polêmica do vínculo podia estender a discussão até as instâncias superiores.

O acordo era exaltado como uma forma de administrar conflitos apenas entre as partes. Certo advogado me disse: "Eu gosto do acordo, nele as partes negociam sozinhas." Em outra ocasião, presenciei um advogado elogiando determinada juíza. "A senhora é a musa da conciliação." Esse discurso oficial contrastou absurdamente com a prática social. Os acordos da justiça do trabalho, e, em especial, do trabalho doméstico remunerado não eram acordos apenas entre as partes. E nisso diferenciam-se da ADR.

O papel do juiz na condução do acordo era de direcionar o acordo. Os acordos produzidos em audiência eram dirigidos pelo juiz. É o próprio judiciário que fez sugir, nas palavras de Nader (1994), uma "harmonia coercitiva". Como quer John French (2001), tratavase de uma "justiça com desconto". Uma das frases mais comuns de se ouvir dos juízes nessas audiências era: "Se não fechar o acordo, isso daí vai demorar anos na justiça. E ainda tem que esse negócio de vínculo de doméstica é controvertido. O tribunal pode até decidir que não tem vínculo e você perde tudo."

Era comum ouvir-se também dos juízes, “quanto mais eu ouvir suas testemunhas, doutor advogado, pior ficará o acordo para o senhor." O "Princípio da Celeridade" tornou-se, então, uma obrigação. As empregadas domésticas, por seu turno, teimavam em desafiar essa ordem. Mesmo com a práticas dos advogados, como me foi relatado por uma advogada, de forçar um

\footnotetext{
${ }^{5}$ As reservas indígenas americanas foram convencidas por emissários de Washington a encarar o lixo nuclear como uma solução vencer ou vencer - saindo da miséria econômica e ao mesmo tempo contribuindo para com o seu país. Grupos de ativistas do meio ambiente estão sendo pressionados mediante reuniões de consenso, também supostamente de tipo vencer ou vencer. Problemas familiares são mediados, enquanto na Califórnia, a mediação é obrigatória. Em Washington há um Escritório Governamental de Planejamento de Conferências de Consenso. Nas escolas-guetos treinam-se os "criadores de caso" a solucionar disputas, quem sabe recheando seus estômagos com cafés da manhã quentinhos. E agora temos um presidente cognominado "Presidente do Consenso". As bases do posicionamento do presidente Clinton quanto ao consenso já foram documentadas, que estudou uma comunidade batista sulista da Geórgia, fornecendo-nos os significados culturais de uma explosão da ADR. Ela sugere que a equação contemporânea cristianismo mais harmonia inspirou a evitação da lei, a aversão à lei e o valor do consenso: "uma estratégia que modificou o conflito..." (NADER,1994)
} 
acordo. "Nós, os advogados forçamos mesmo, até quando a pessoa não quer o acordo. Imagina se não tem acordo. É um caos.”

\section{O JUIZ, A DOMÉSTICA E A POLÍCIA}

Quero trazer ao texto uma segunda parte da entrevista com determinado juiz. Em certo momento da nossa entrevista, já ao final dela, eu perguntei, "Como é julgar para o senhor que foi juiz por tanto tempo?". Fiz essa pergunta, uma vez que, ele mesmo me informou ter sido juiz e desembargador do trabalho por muitos anos. A resposta dele foi rápida:

O trabalho do juiz é primeiro o de neutralizar o advogado. O advogado é uma figura que sempre precisa ser neutralizada. O advogado da Reclamante sempre vai pedir tudo. Sempre vai falar que o empregador não pagou nada. Por sua vez, o advogado da Reclamada sempre fala que está tudo pago. Daí só resta uma opção, olhar para as partes e desenvolver um faro. Faro como o faro policial. A polícia não faz isso? De descobrir as coisas olhando. O juiz também. Assim que se julga.

A sua fala fez menção à já explicada lógica do contraditório. Percebi o aparecimento de um elemento inesperado na fala do juiz: a polícia. De outro lado, também, a figura da polícia estava na fala das domésticas do tribunal. O juiz é que nem a polícia, pode fazer qualquer coisa. Dizia-me uma das domésticas entrevistadas.

Ou seja, os atores dessas cenas falaram da polícia. Ela quase entrou em cena. Existiu um motivo dessa figura, tão longe da realidade dessa Justiça, estar presente no imaginário dessas pessoas. Retornei ao tema da igualdade no Brasil, como pesquisado no primeiro capítulo, para explicar esse fenômeno. Roberto Cardoso de Oliveira (2011) mencionou a dificuldade de implementar, no âmbito das articulações do Espaço Público, os princípios estabelecidos formalmente e dominantes no universo do discurso de uma esfera pública. Existe, para o autor, uma espécie de substrato moral. Esse substrato serve, entre nós, para identificar as pessoas no espaço público, desigualando os sujeitos. 
Para ilustrar, o autor relembra um episódio famoso na cidade de Brasília, quando alguns jovens atearam fogo em um indígena. A justificativa foi que ele parecia um mendigo. Ou seja, o fato de ser um mendigo tirava desse sujeito o seu "substrato moral de pessoa digna". E a polícia também é identificada como órgão capaz de fazer essa diferenciação.

\begin{abstract}
A propósito, nem sempre que se reivindica respeito a direitos e reconhecimento da dignidade do cidadão se demanda tratamento uniforme, como revela, por exemplo, a pesquisa de Marcus Cardoso (2010) sobre a instalação do Grupamento de Policiamento em Áreas Especiais (GPAE) no Cantagalo e Pavão-Pavãozinho. A fala dos moradores sobre o que seria um tratamento respeitoso e adequado por parte da polícia sugeria que tal tratamento não precisava ser igual àquele dirigido aos moradores dos bairros de Copacabana e Ipanema, que rodeiam a favela. Será que poderíamos identificar aqui diferenças no exercício e na afirmação da dignidade do cidadão, abrangendo distinções de tratamento sem desrespeitar direitos aos olhos dos atores? Quais seriam suas implicações para a cidadania? Em que medida a elucidação dessas diferenças poderia contribuir para uma melhor delimitação dos campos de vigência de direitos e privilégios, com respaldo social, viabilizando a conformação de um mundo cívico partilhado pelos cidadãos, e reduzindo a sensação de arbitrariedade na distribuição-alocação de direitos? (OLIVEIRA, 2011)
\end{abstract}

\title{
7. CONSIDERAÇÕES FINAIS
}

Durante todos esses meses de pesquisa, pude presenciar os inúmeros discursos, afetos ao direito, que se repetiam nessa administração institucional de conflitos do trabalho doméstico remunerado, nessas audiências. Entendi a necessidade de problematizar um desses discursos, aquele sobre o acordo judicial. Remontei, assim, questões sobre a desigualdade, para tentar compreender as representações jurídicas sobre o vínculo de emprego doméstico. Mais do que simplesmente existir por um acaso ou por um acidente, a desigualdade e a hierarquia tornamse valores.

As diversas representações jurídicas - discursos dos magistrados e dos advogados e a própria condução das audiências - enfatizavam a necessidade dos acordos judiciais como forma privilegiada de administrar esse conflito. Esses mesmos acordos eram sempre simbolizados cordos em que "todos ganham", realizados "por livre e espontânea" vontade. Nesse sentido, busquei uma compreensão das práticas dessa conciliação, mostrando como não se trata de um espaço informal ou de um procedimento célere. 
A empregada doméstica é, na prática, levada a aceitar um acordo "com desconto", sob a ameaça de perder os benefícios da informalidade e da celeridade. Para levar a cabo esses acordos, toda uma simbologia é utilizada, geralmente enfatizando a desigualdade entre a empregada doméstica e o juiz ou mesmo entre ela e seu advogado. Do começo ao fim da audiência, tudo fez relembrar o par hierarquia e desigualdade. Com certeza, a Emenda Constitucional $\mathrm{n}^{\circ} 73$ de 2013 foi a tentativa de um avanço no sentido de igualar pessoas. No entanto, um outro obstáculo, muito mais profundo, se colocou. Trata-se de uma cultura jurídica rigidamente hierárquica.

\section{REFERÊNCIAS BIBLIOGRÁFICAS}

BARBOSA, Ruy. Oração aos moços. São Paulo: Hedra, 1956.

BRITES, Jurema Gorski. Trabalho doméstico: questões, leituras e políticas. Cadernos de pesquisa, v. 43, n. 149, p. 422-451, 2013.

BRUSCHINI, Cristina. Trabalho doméstico: inatividade econômica ou trabalho nãoremunerado? Revista brasileira de estudos de população, v. 23, n. 2, p. 331-353, 2006.

CARDOSO, Adalberto Moreira; LAGE, Telma. As normas e os fatos: desenho e efetividade das instituições de regulação do mercado de trabalho no Brasil. FGV Editora, 2007.

OLIVEIRA, Luís Roberto Cardoso de. Concepções de igualdade e cidadania. Contemporânea - Revista de Sociologia da UFSCar. São Carlos, Departamento e Programa de Pós-Graduação em Sociologia, 2011, n. 1, p. 35-48.

DAVIS, Shelton H. Antropologia do Direito: estudo comparativo das categorias dedívida e contrato. Rio de Janeiro: Zahar Editores, 1973.

FONTAINHA, Fernando. O "Grande Oral”: Professores e juízes no campo jurídico francês. Revista Ética e Filosofia Política, v. 2, n. 12, p. 43-60, 2010.

FRENCH, John D. Afogados em leis: a CLT e a cultura política dos trabalhadores brasileiros. São Paulo: Fundação Perseu Abramo, 2001.

GERALDO, Pedro Heitor Barros. A audiência judicial em ação: uma etnografia das interações entre juristas e jurisdicionados na França. Revista Direito GV, v. 9, n. 2, p. 635-658, 2013.

GOFFMAN, Erving. A representação do eu na vida cotidiana. Petrópolis:Vozes, 2013.

GOMES, Ângela de Castro; SILVA, Fernando Teixeira da. Os direitos sociais e humanos dos trabalhadores no Brasil: A título de apresentação. In: GOMES, Ângela de Castro; SILVA, 
Fernando Teixeira da. (Orgs.) A Justiça do Trabalho e sua História. Campinas: Editora Unicamp, 2013.

GOMES, F. Medina; SILVA, Gabriel Borges da. "Lavo, passo e cozinho na sua casa e pros seus filhos, mas meu filho que mora comigo fica largado na favela": Reflexões sobre suspeição e precariedade nos casos do 'Cria de Favela' e da 'Empregada Doméstica'. Antropolítica: Revista Contemporânea de Antropologia, v. 03, p. 189, 2020.

GOMES, Fabio Medina. O conflito invisível: administrando o conflito entre patrões e empregadas domésticas na Justiça do Trabalho. In: Lenin Pires. (Org.). Discursos de Poder e Segurança Pública. 1ed.: Fundação Cecierj, 2016a, v. único, p. 279-306.

"Não é que elas tenham menos direitos, acontece que elas não têm os mesmos direitos que os outros": Representações Jurídicas sobre igualdade e trabalho doméstico. In: Lilian Baltman Emerique; Sayonara Grillo Coutinho Leonardo da Silva; Ivan Simões Garcia. (Org.). Direitos Humanos e Trabalho Decente. 01ed.Belo Horizonte: Editora Forum, 2016b, v. 01, p. 206-234.

Entre juízas, domésticas e patroas: análise de três discursos de gênero. Sociologias Plurais, v. 3, p. 36-53, 2015a.

Amizades muito hierárquicas: direitos e emoções nas relações entre domésticas e patroas. CADERNOS DE CAMPO (USP), v. 24, p. 290-314, 2015 b.

HIRATA, Helena. Nova divisão sexual do trabalho? Um olhar voltado para a empresa e a sociedade. São Paulo: Boitempo, 2013.

KANT DE LIMA. Sensibilidades jurídicas, saber e poder: bases culturais de alguns aspectos do direito brasileiro em uma perspectiva comparada. Anuário antropológico, v. 2, 2009.

MELO, Hildete Pereira de. O serviço doméstico remunerado no Brasil: de criadas atrabalhadoras. Instituto de Pesquisa Econômica Aplicada, Serviço Editorial, 1998.

MENDES, R. L. T. Dilemas da decisão judicial. As representações de juízes brasileiros sobre o princípio do livre convencimento motivado. Rio de Janeiro: Tese de doutorado apresentada no Programa de Pós-Graduação em Direito da Universidade Gama Filho, 2008.

NADER, Laura. Harmonia Coerciva: a economia política dos modelos jurídicos. Revista Brasileira de Ciências Sociais, v. 29, n. 9, p. 18-29, 1994.

OLIVEIRA, K. G.; FREITAS, R. V . Justiça do Trabalho e a Administração dos Conflitos nas audiências de conciliação. In: Roberto Kant de Lima; Maria Stella Faria de Amorim; Michel Lobo Toledo Lima.. (Org.). Administração de Conflitos e Cidadania: problemas e perspectivas IV. 1ed.Rio de Janeiro: Autografia, 2020, v. 33, p. 363-374.

RANGEL, Victor Cesar Torres de Mello; LIMA, Lana Lage da Gama. As práticas de atendimento as mulheres vítimas de violência em um núcleo de uma cidade do interior do estado do Rio de Janeiro. Outras Publicações, 2010.

SAFFIOTI, Heleieth I. B. Emprego doméstico e capitalismo. Petropólis: Vozes, 1978. 
SILVA, Sayonara Grillo. Relações Coletivas de Trabalho. Configurações Institucionais no Brasil Contemporâneo. São Paulo: LTr, 2008.

SILVA, Wanise; GOMES, Fabio. Que horas ela volta? O trabalho doméstico no Brasil: da ficção à realidade. In: Eddy Chávez Huanca. (Org.). Los derechos de la mujer en el cine. $1^{\mathrm{a}}$ ed. Lima, Peru: Continental, 2019, p. 353-364.

SPERANZA, Clarice Gontarski. Nos termos das concliliações: os acordos entre mineiros de carvão do Rio Grande do Sul e seus patrões na Justiça do Trabalho entre 1946 e 1954. In: GOMES, Ângela de Castro; SILVA, Fernando Teixeira da. A Justiça do Trabalho e sua História. Campinas: Editora Unicamp, 2013.

TOLEDO LIMA, Michel Lobo. Sentenciando acordos: a administração de conflitos em um juizado especial criminal da baixada fluminense. Trabalho apresentado à Reunião da $\mathrm{ABCP}$, 2014. 